International Journal of Pure and Applied Mathematics

Volume 93 No. 3 2014, 361-367

ISSN: 1311-8080 (printed version); ISSN: 1314-3395 (on-line version)

url: http://www.ijpam.eu

doi: http://dx.doi.org/10.12732/ijpam.v93i3.6

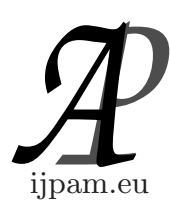

\title{
APPLICATION OF GENERALIZED VAGUE SOFT EXPERT SET IN DECISION MAKING
}

\author{
Khaleed Alhazaymeh ${ }^{1}$, Nasruddin Hassan ${ }^{2} \S$ \\ ${ }^{1,2}$ School of Mathematical Sciences \\ Universiti Kebangsaan Malaysia \\ 43600 UKM, Bangi Selangor, MALAYSIA
}

\begin{abstract}
Generalized vague soft expert sets can be used to analyze decisionmaking problems. In this work we give an application of this concept which we have earlier introduced, in a decision-making problem.
\end{abstract}

AMS Subject Classification: 03B52, 03E72

Key Words: fuzzy sot expert set, generalized fuzzy soft expert set, soft expert set, vague soft set

\section{Introduction}

One of the most important new mathematical tools is soft set theory defined by Molodtsov [1]. Alkhazaleh et al. [2], [3], [4] and Salleh et al. [5] extended their studies on fuzzy soft sets, while Alhazaymeh et. al [6], Hassan and Alhazaymeh [7] and Alhazaymeh and Hassan [8], [9], [10],[11], [12], [13], [14] worked on vague soft sets. Adam and Hassan [15] proposed multi Q-fuzzy parameterized soft set and Varnamkhasti and Hassan [16], [17] applied fuzzy sets to genetic algorithms. In this paper we further apply generalized vague soft expert set to a decision-making problem. Thus decision making problems are now not limited to certainty data such as goal programming [18], [19], [20], [21], [22], [23], [24], [25], [26], [27], [28], [29] and data envelopment analysis [30], [31], [32].

Received: November 26, 2013

(C) 2014 Academic Publications, Ltd. url: www.acadpubl.eu

${ }^{\S}$ Correspondence author 


\section{An Application of Generalized Vague Soft Expert Set}

In this section, we illustrate an application of generalized vague soft expert set in a decision making problem. We suppose that one of the direct selling companies wishes to evaluate three products from a manufacturer and choose the most suitable product for it to market. Its three alternatives are $U=\left\{u_{1}, u_{2}, u_{3}\right\}$, with three parameters $E=\left\{e_{1}, e_{2}, e_{3}\right\}$. The parameters $e_{\mathrm{i}}(i=1,2,3)$ stands for "effect of the product", "utilization of the product" and "expired date of the product". Let $X=\{p, q, r\}$ be a set of a committee members. After a few series of consultations, the following generalized vague soft expert set was constructed.

$$
\begin{aligned}
& \left(F_{\mu}, Z\right)=\left\{\left(\left(e_{1}, p, 1\right),\left\{\frac{u_{1}}{\langle 0.5,0.5\rangle}, \frac{u_{2}}{\langle 0.6,0.8\rangle}, \frac{u_{3}}{\langle 0,0\rangle}\right\}, 0.2\right),\right. \\
& \left(\left(e_{1}, q, 1\right),\left\{\frac{u_{1}}{\langle 0.3,0.6\rangle}, \frac{u_{2}}{\langle 0.9,0.9\rangle}, \frac{u_{3}}{\langle 1,1\rangle}\right\}, 0.5\right),\left(\left(e_{1}, r, 1\right),\left\{\frac{u_{1}}{\langle 0.4,0.8\rangle}, \frac{u_{2}}{\langle 0.2,0.2\rangle}, \frac{u_{3}}{\langle 0.9,0.9\rangle}\right\}, 0.2\right), \\
& \left(\left(e_{2}, p, 1\right),\left\{\frac{u_{1}}{\langle 0.2,0.8\rangle}, \frac{u_{2}}{\langle 0.4,0.7\rangle}, \frac{u_{3}}{\langle 0.5,0.6\rangle}\right\}, 0.8\right),\left(\left(e_{2}, q, 1\right),\left\{\frac{u_{1}}{\langle 0.3,0.4\rangle}, \frac{u_{2}}{\langle 0.4,0.5\rangle}, \frac{u_{3}}{\langle 0.6,0.8\rangle}\right\}, 0.3\right), \\
& \left.\left(\left(e_{2}, r, 1\right),\left\{\frac{u_{1}}{\langle 0.1,0.1\rangle}, \frac{u_{2}}{\langle 0.8,0.9\rangle}, \frac{u_{3}}{\langle 0.3,0.4\rangle}\right\}, 0.6\right)\right\},\left(\left(e_{3}, p, 1\right),\left\{\frac{u_{1}}{\langle 0.3,0.6\rangle}, \frac{u_{2}}{\langle 0.6,0.6\rangle}, \frac{u_{3}}{\langle 0.5,0.5\rangle}\right\}, 0.9\right), \\
& \left(\left(e_{3}, q, 1\right),\left\{\frac{u_{1}}{\langle 0.1,0.2\rangle}, \frac{u_{2}}{\langle 0.2,0.6\rangle}, \frac{u_{3}}{\langle 0.40 .6\rangle}\right\}, 0.2\right),\left(\left(e_{3}, r, 1\right),\left\{\frac{u_{1}}{\langle 0.3,0.7\rangle}, \frac{u_{2}}{\langle 0.1,0.3\rangle}, \frac{u_{3}}{\langle 0.3,0.6\rangle}\right\}, 0.5\right), \\
& \left(\left(e_{1}, p, 0\right),\left\{\frac{u_{1}}{\langle 0.1,0.1\rangle}, \frac{u_{2}}{\langle 0.8,0.9\rangle}, \frac{u_{3}}{\langle 0.30 .3\rangle}\right\}, 0.6\right),\left(\left(e_{1}, q, 0\right),\left\{\frac{u_{1}}{\langle 0.0 .0 .0 .4\rangle}, \frac{u_{2}}{\langle 0.40 .5\rangle}, \frac{u_{3}}{\langle 0.6,0.8\rangle}\right\}, 0.8\right), \\
& \left(\left(e_{1}, r, 0\right),\left\{\frac{u_{1}}{\langle 0.3,0.7\rangle}, \frac{u_{2}}{\langle 0.1,0.3\rangle}, \frac{u_{3}}{\langle 0.3,0.6\rangle}\right\}, 0.1\right),\left(\left(e_{2}, p, 0\right),\left\{\frac{u_{1}}{\langle 0.5,0.5\rangle}, \frac{u_{2}}{\langle 0.6,0.8\rangle}, \frac{u_{3}}{\langle 0,0\rangle}\right\}, 0.3\right), \\
& \left(\left(e_{2}, q, 0\right),\left\{\frac{u_{1}}{\langle 0.3,0.6\rangle}, \frac{u_{2}}{\langle 0.9,0.9\rangle}, \frac{u_{3}}{\langle 1,1\rangle}\right\}, 0.6\right),\left(\left(e_{2}, r, 0\right),\left\{\frac{u_{1}}{\langle 0.4,0.8\rangle}, \frac{u_{2}}{\langle 0.2,0.2\rangle}, \frac{u_{3}}{\langle 0.9,0.9\rangle}\right\}, 0.7\right), \\
& \left(\left(e_{3}, p, 0\right),\left\{\frac{u_{1}}{\langle 0.3,0.6\rangle}, \frac{u_{2}}{\langle 0.6,0.6\rangle}, \frac{u_{3}}{\langle 0.5,0.5\rangle}\right\}, 0.9\right),\left(\left(e_{3}, q, 0\right),\left\{\frac{u_{1}}{\langle 0.1,0.2\rangle}, \frac{u_{2}}{\langle 0.2,0.6\rangle}, \frac{u_{3}}{\langle 0.4,0.6\rangle}\right\}, 0.6\right), \\
& \left.\left(\left(e_{3}, r, 0\right),\left\{\frac{u_{1}}{\langle 0.3,0.7\rangle}, \frac{u_{2}}{\langle 0.1,0.3\rangle}, \frac{u_{3}}{\langle 0.3,0.6\rangle}\right\}, 0.8\right)\right\} .
\end{aligned}
$$

Table 1 and 2 present the agree-generalized vague soft expert set and disagree-generalized vague soft expert set respectively.

Table 1: Agree-generalized vague soft expert set

\begin{tabular}{rcccc}
\hline$U$ & $u_{1}$ & $u_{2}$ & $u_{3}$ & \\
\hline$\left(e_{1}, p\right)$ & $\langle 0.5,0.5\rangle$ & $\langle 0.6,0.8\rangle$ & $\langle 0,0\rangle$ & 0.2 \\
$\left(e_{1}, q\right)$ & $\langle 0.3,0.6\rangle$ & $\langle 0.9,0.9\rangle$ & $\langle 1,1\rangle$ & 0.5 \\
$\left(e_{1}, r\right)$ & $\langle 0.4,0.8\rangle$ & $\langle 0.2,0.2\rangle$ & $\langle 0.9,0.9\rangle$ & 0.2 \\
$\left(e_{2}, p\right)$ & $\langle 0.2,0.8\rangle$ & $\langle 0.4,0.7\rangle$ & $\langle 0.5,0.6\rangle$ & 0.8 \\
$\left(e_{2}, q\right)$ & $\langle 0.3,0.4\rangle$ & $\langle 0.4,0.5\rangle$ & $\langle 0.6,0.8\rangle$ & 0.3 \\
$\left(e_{2}, r\right)$ & $\langle 0.1,0.1\rangle$ & $\langle 0.8,0.9\rangle$ & $\langle 0.3,0.4\rangle$ & 0.6 \\
$\left(e_{3}, p\right)$ & $\langle 0.3,0.6\rangle$ & $\langle 0.6,0.6\rangle$ & $\langle 0.5,0.5\rangle$ & 0.9 \\
$\left(e_{3}, q\right)$ & $\langle 0.1,0.2\rangle$ & $\langle 0.2,0.6\rangle$ & $\langle 0.4,0.6\rangle$ & 0.2 \\
$\left(e_{3}, r\right)$ & $\langle 0.3,0.7\rangle$ & $\langle 0.1,0.3\rangle$ & $\langle 0.3,0.6\rangle$ & 0.5 \\
\hline
\end{tabular}


Table 2: Disagree-generalized vague soft expert set

\begin{tabular}{rcccc}
\hline$U$ & $u_{1}$ & $u_{2}$ & $u_{3}$ & \\
\hline$\left(e_{1}, p\right)$ & $\langle 0.1,0.1\rangle$ & $\langle 0.8,0.9\rangle$ & $\langle 0.3,0.3\rangle$ & 0.6 \\
$\left(e_{1}, q\right)$ & $\langle 0.3,0.4\rangle$ & $\langle 0.4,0.5\rangle$ & $\langle 0.6,0.8\rangle$ & 0.8 \\
$\left(e_{1}, r\right)$ & $\langle 0.3,0.7\rangle$ & $\langle 0.1,0.3\rangle$ & $\langle 0.3,0.6\rangle$ & 0.1 \\
$\left(e_{2}, p\right)$ & $\langle 0.5,0.5\rangle$ & $\langle 0.6,0.8\rangle$ & $\langle 0,0\rangle$ & 0.3 \\
$\left(e_{2}, q\right)$ & $\langle 0.3,0.6\rangle$ & $\langle 0.9,0.9\rangle$ & $\langle 1,1\rangle$ & 0.6 \\
$\left(e_{2}, r\right)$ & $\langle 0.4,0.4\rangle$ & $\langle 0.2,0.2\rangle$ & $\langle 0.9,0.9\rangle$ & 0.7 \\
$\left(e_{3}, p\right)$ & $\langle 0.3,0.6\rangle$ & $\langle 0.6,0.6\rangle$ & $\langle 0.5,0.5\rangle$ & 0.9 \\
$\left(e_{3}, q\right)$ & $\langle 0.1,0.2\rangle$ & $\langle 0.2,0.6\rangle$ & $\langle 0.4,0.6\rangle$ & 0.6 \\
$\left(e_{3}, r\right)$ & $\langle 0.3,0.7\rangle$ & $\langle 0.1,0.3\rangle$ & $\langle 0.3,0.6\rangle$ & 0.8 \\
\hline
\end{tabular}

We subtract the false-membership function from the truth-membership function and we mark the highest numerical grade in each row as shown in Table 3 and Table 4 for agree-generalized vague soft expert set and disagree-generalized vague soft expert set respectively. Then, we calculate the score of each product in agree-generalized and disagree-generalized vague soft expert sets by taking the sum of the products of these numerical grades with the corresponding values of $\lambda$. We calculate the final score by subtracting the scores of the potential marketing products in the agree-generalized vague soft expert set from the scores in the disagree-generalized vague soft expert set. The marketing product with the highest score is the desired product to be marketed through direct selling by the company.

Table 3: Agree-generalized vague soft expert set

\begin{tabular}{rcccc}
\hline$U$ & $u_{1}$ & $u_{2}$ & $u_{3}$ & $\lambda$ \\
\hline$\left(e_{1}, p\right)$ & $\underline{0}$ & -0.2 & 0 & 0.2 \\
$\left(e_{1}, q\right)$ & -0.3 & $\underline{0}$ & $\underline{0}$ & 0.5 \\
$\left(e_{1}, r\right)$ & -0.4 & $\underline{0}$ & $\underline{0}$ & 0.2 \\
$\left(e_{2}, p\right)$ & -0.6 & -0.3 & $\underline{-0.1}$ & 0.8 \\
$\left(e_{2}, q\right)$ & $\underline{-0.1}$ & $\underline{-0.1}$ & -0.2 & 0.3 \\
$\left(e_{2}, r\right)$ & $\underline{0}$ & -0.1 & -0.1 & 0.6 \\
$\left(e_{3}, p\right)$ & -0.3 & $\underline{0}$ & $\underline{0}$ & 0.9 \\
$\left(e_{3}, q\right)$ & $\underline{-0.1}$ & -0.4 & -0.2 & 0.2 \\
$\left(e_{3}, r\right)$ & -0.4 & $\underline{-0.2}$ & -0.3 & 0.5 \\
\hline
\end{tabular}


The scores of $u_{i}$ are computed by using the data in Table 3 .

$\operatorname{score}\left(u_{1}\right)=(0 * 0.2)+(-0.1 * 0.3)+(0 * 0.6)+(-0.1 * 0.2)=-0.05$,

$\operatorname{score}\left(u_{2}\right)=(0 * 0.5)+(0 * 0.2)+(-0.1 * 0.3)+(0 * 0.9)+(-0.2 * 0.5)=-0.13$,

$\operatorname{score}\left(u_{3}\right)=(0 * 0.5)+(0 * 0.2)+(-0.1 * 0.8)+(0 * 0.9)=-0.08$,

Table 4: Disagree-generalized vague soft expert set

\begin{tabular}{rcccc}
\hline$U$ & $u_{1}$ & $u_{2}$ & $u_{3}$ & $\lambda$ \\
\hline$\left(e_{1}, p\right)$ & $\underline{0}$ & -0.1 & 0 & 0.6 \\
$\left(e_{1}, q\right)$ & $\underline{-0.1}$ & $\underline{-0.1}$ & -0.2 & 0.8 \\
$\left(e_{1}, r\right)$ & -0.3 & $\underline{-0.2}$ & -0.3 & 0.1 \\
$\left(e_{2}, p\right)$ & $\underline{0}$ & -0.2 & $\underline{0}$ & 0.3 \\
$\left(e_{2}, q\right)$ & -0.3 & $\underline{0}$ & $\underline{0}$ & 0.6 \\
$\left(e_{2}, r\right)$ & $\underline{0}$ & $\underline{0}$ & $\underline{0}$ & 0.7 \\
$\left(e_{3}, p\right)$ & -0.3 & $\underline{0}$ & $\underline{0}$ & 0.9 \\
$\left(e_{3}, q\right)$ & $\underline{-0.1}$ & -0.4 & -0.2 & 0.6 \\
$\left(e_{3}, r\right)$ & -0.4 & $\underline{-0.2}$ & -0.3 & 0.8 \\
\hline
\end{tabular}

Compute the scores of $u_{i}$ by using the data in Table 4 .

$\operatorname{score}\left(u_{1}\right)=(0 * 0.6)+(-0.1 * 0.8)+(0 * 0.3)+(0 * 0.7)+(-0.1 * 0.6)=-0.14$,

$\operatorname{score}\left(u_{2}\right)=(-.1 * 0.8)+(-0.2 * 0.1)+(0 * 0.6)+(0 * 0.7)+(0 * 0.9)+(-0.2 * 0.8)=-0.26$, $\operatorname{score}\left(u_{3}\right)=(0 * 0.3)+(0 * 0.6)+(0 * 0.7)+(0 * 0.9)=0$.

The final score of $\left(u_{i}\right)$ as follows:

$\operatorname{score}\left(u_{1}\right)=-0.05+0.14=0.09$,

$\operatorname{score}\left(u_{2}\right)=-0.13+0.26=0.13$

$\operatorname{score}\left(u_{3}\right)=-0.08+0=-0.08$,

Thus the management committee decision is to choose product $u_{2}$.

\section{Conclusion}

Research and the development of the application of vague soft set in decision-making problems are ongoing. This new application not only provide a significant addition to existing theories for handling uncertainties, but also leads to potential areas of further research and pertinent applications. 


\section{Acknowledgments}

We are indebted to Universiti Kebangsaan Malaysia for funding this research under the the grant BKBP-FST-K005560.

\section{References}

[1] D.A.Molodtsov, Soft set theory-first result, Computers and Mathematics with Applications, 37(1999), 19-31.

[2] S. Alkhazaleh, A. R. Salleh and N. Hassan, Soft multisets theory, Applied Mathematical Sciences, 5 (72) (2011), 3561 - 3573.

[3] S. Alkhazaleh, A. R. Salleh and N. Hassan, Possibility fuzzy soft set, Advances in Decision Sciences, Article ID 479756, 18 pages doi:10.1155/2011/479756.

[4] S. Alkhazaleh, A. R. Salleh and N. Hassan, Fuzzy parameterized interval-valued fuzzy soft set, Applied Mathematical Sciences, 5 (67) (2011), 3335-3346.

[5] A. R. Salleh, S. Alkhazaleh, N. Hassan and A.G. Ahmad, Multiparameterized soft set, Journal of Mathematics and Statistics, 8 (1) (2012), 92-97.

[6] K. Alhazaymeh, S. Abdul Halim, A. R. Salleh and N. Hassan, Soft intuitionistic fuzzy sets, Applied Mathematical Sciences, 6 (54) (2012), 2669-2680.

[7] N. Hassan and K. Alhazaymeh, Vague soft expert set theory, AIP Conference Proceedings, 1522 (2013), 953-958 ; doi: 10.1063/1.4801233.

[8] K. Alhazaymeh and N. Hassan, Generalized vague soft set and its applications, International Journal of Pure and Applied Mathematics, 77 (3) (2012), 391-401.

[9] K. Alhazaymeh and N. Hassan, Possibility vague soft set and its application in decision making, International Journal of Pure and Applied Mathematics, 77 (4) (2012), 549-563.

[10] K. Alhazaymeh and N. Hassan, Interval-valued vague soft sets and its application, Advances in Fuzzy Systems, Article ID 208489, 7 pages. doi:10.1155/2012/208489.

[11] K.Alhazaymeh and N.Hassan, Possibility interval-valued vague soft set, Applied Mathematical Sciences, 7 (140) (2013), 6989-6994.

[12] K.Alhazaymeh and N.Hassan, Generalized interval-valued vague soft set, Applied Mathematical Sciences, 7 (140) (2013), 6983-6988.

[13] K.Alhazaymeh and N.Hassan, Generalized vague soft expert set, International Journal of Pure and Applied Mathematics, (in press).

[14] K. Alhazaymeh and N. Hassan, Mapping on generalized vague soft expert set, International Journal of Pure and Applied Mathematics, (in press). 
[15] F. Adam and N. Hassan, Multi Q-fuzzy parameterized soft set and its application, Journal of Intelligent and Fuzzy System, (in press).

[16] M. Varnamkhasti and N. Hassan, A hybrid of adaptive neuro-fuzzy inference system and genetic algorithm, Journal of Intelligent and Fuzzy Systems, 25 (3) (2013), 793-796.

[17] M. Varnamkhasti and N. Hassan, Neurogenetic algorithm for solving combinatorial engineering problems, Journal of Applied Mathematics, Vol. (2012), Article ID 253714, 12 pages. doi:10.1155/2012/253714.

[18] N. Hassan, K.B. Hassan, S.S Yatim and S.A. Yusof, Optimizing fertilizer compounds and minimizing the cost of cucumber production using the goal programming approach, American-Eurasian Journal of Sustainable Agriculture, 7 (2) (2013), 45-49.

[19] N. Hassan, H.H.M. Hamzah and S.M.M. Zain, A goal programming approach for rubber production in Malaysia, American-Eurasian Journal of Sustainable Agriculture, 7 (2) (2013), 50-53.

[20] N. Hassan, N. Ahmad and W.M.W. Aminuddin, Selection of mobile network operator using analytic hierarchy process, Advances in Natural and Applied Sciences, $\mathbf{7}$ (1) (2013), 1-5.

[21] N. Hassan, A.H.M. Pazil, N.S. Idris and N.F. Razman, A goal programming model for bakery production, Advances in Environmental Biology, 7 (1) (2013), 187-190.

[22] N. Hassan, S. Safiai, N.H.M. Raduan and Z. Ayop, Goal programming formulation in nutrient management for chilli plantation in Sungai Buloh Malaysia, Advances in Environmental Biology, 6 (12) (2012), 4008-4012.

[23] N. Hassan and B.A. Halim, Mathematical modelling approach to the management of recreational tourism activities at Wetland Putrajaya (in Malay), Sains Malaysiana, 41 (9) (2012), 1155-1161.

[24] N. Hassan and L.L. Loon, Goal programming with utility function for funding allocation of a university library, Applied Mathematical Sciences, 6 (110) (2012), 5487-5493.

[25] N. Hassan, L.W. Siew and S.Y. Shen, Portfolio decision analysis with maximin criterion in the Malaysian stock market, Applied Mathematical Sciences, 6 (110) (2012), 5483-5486.

[26] N. Hassan and S. Sahrin, A mathematical model of nutrient management for pineapple cultivation in Malaysia, Advances in Environmental Biology, 6 (5) (2012), 1868-1872.

[27] N. Hassan and Z. Ayop, A goal programming approach for food product distribution of small and medium enterprises, Advances in Environmental Biology, 6 (2) (2012), 510-513. 
[28] N. Hassan and S.B.M. Basir, A goal programming model for scheduling political campaign: A case study in Kabupaten Kampar, Riau, Indonesia (in Malay), Journal of Quality Measurement and Analysis, 5 (2) (2009), 99-107.

[29] N. Hassan, D.F. Azmi, T.S. Guan and L.W. Hoe, A goal programming approach for library acquisition allocation, Applied Mathematical Sciences, 7 (140) (2013), 6977-6981.

[30] N. Hassan and M.M. Tabar, The relationship of multiple objectives linear programming and data envelopment analysis, Australian Journal of Basic and Applied Sciences, 5 (11) (2011), 1711-1714.

[31] N. Hassan, M.M. Tabar and P. Shabanzade, Resolving multi objectives resource allocation problem based on inputs and outputs using data envelopment analysis method, Australian Journal of Basic and Applied Sciences, 4 (10) (2010), 53205325 .

[32] N. Hassan, M.M. Tabar and P. Shabanzade, A ranking model of data envelopment analysis as a centralized multi objective resource allocation problem tool, Australian Journal of Basic and Applied Science, 4 (10) (2010), 5306-5313. 
